\title{
Ali Turkdogan
}

Assoc. Proof, Sivas Cumhuriyet University, Department of Mathematics and Science, Turkey. Email:aliturkdogan@hotmail.com

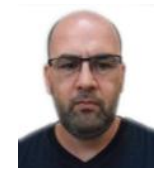

\begin{abstract}
The purpose of the research is to develop a valid and reliable attitude scale that can measure the attitudes of math and science teachers (315) and teacher candidates (105) towards mistakes and instant feedback. In the validity studies, the exploratory factor analysis was made with the SPS1S 8.0 package program after that the confirmatory factor analysis was made with Lisrel 8.8 software. To develop the scale; 1. Creation of Item Pool 2. Obtaining Expert Opinion, 3. Creation of Pre-Trial Form 4. Factor Analysis is made. According to factor analysis; Kaiser Meyer Olkin (KMO) rate; .808; Bartlett test result: 2148,354; Cronbach alpha reliability coefficient for the whole scale: .829. According to confirmatory factor analysis: Root Mean Square Error of Approximation (RMSEA) .022 (<.05); p-Value for Test of Close Fit .00 (<.05), standardized root mean square residual (SRMR) .014, Goodness of Fit Index (GFI) .75, Adjusted Goodness of Fit Index (AGFI) .69; Normed Fit Index (NFI) .91; Relative Fit Index (RFI) .78; Incremental Fix Index (IFI): .83; Parsimony Goodness of Fit Index (PGFI): .62; Degrees of Freedom: 760; Root Mean Square Residual (RMR): 2.07 and NonNormed Fit Index (NNFI): .88. According to research findings, attitude scale is valid and reliable so it can be used to determine math and science teachers and teacher candidates positive and negative attitudes toward mistake and giving instant feedback to mistake.
\end{abstract}

Keywords: Attitude scale, Mistake, Validity, Reliability, Exploratory factor analysis, Confirmatory factor analysis, Mathematics, Science.

Citation | Ali Turkdogan (2020). Development of an Attitude Scale of Mathematics and Science Teachers towards Mistake and Instant Feedback to the Mistake: A Validity and Reliability Study. Asian Journal of Education and Training, 6(4): 642-650.

History:

Received: 24 September 2020

Revised: 15 October 2020

Accepted: 2 November 9090

Published: 18 Nover 2020

Licensed: This work is licensed under a Creative Commons

Licensed: This work is lice
Attribution 3.0 License (cc) E

Publisher: Asian Online Journal Publishing Group
Funding: This study received no specific financial support.

Competing Interests: The author declares that there are no conflicts of Competing Interests: The author declares th
interests regarding the publication of this paper.

Transparency: The author confirms that the manuscript is an honest, accurate, and transparent account of the study was reported; that no vital features of the study have been omitted; and that any discrepancies from the study as planned have been explained.

Ethical: This study follows all ethical practices during writing.

\section{Contents}

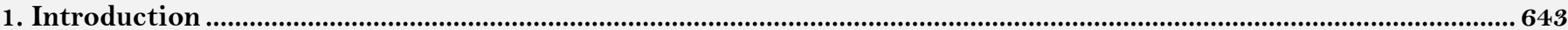

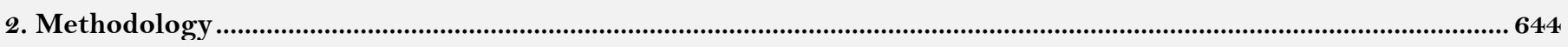

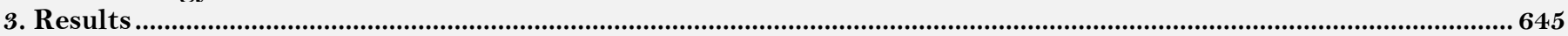

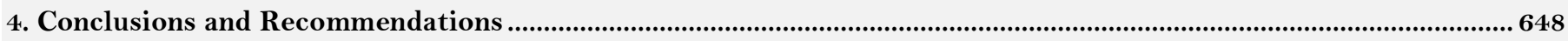

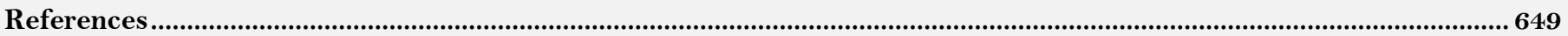




\section{Contribution of this paper to the literature}

Mistake, in a student-centered educational environment, is inevitable and useful. Therefore, it is necessary to examine how teachers give feedback to the mistakes whenever mistakes appear (instant feedback). One of the most important factors that need to create a student-centered environment is to understand the instant feedback. How teachers react when confronted with wrong must be analyzed from various aspects. This study is the first attitude scale development study that examines the factors that affect teachers' feedback.

\section{Introduction}

The student-centered curriculum, which has been the most accepted curriculum in recent years, is based on constructivist theory. $5 \mathrm{E}$ is perhaps the most widely accepted model of how constructivist theory can be applied in classrooms. This model includes an introduction that will attract the student's attention (engage), then explore, explain, elaborate and evaluate steps related to a knowledge, a comprehension or a phenomenon.

In the engage stage, the teacher surveys the students ' prior knowledge of the subject, concept or event. Surely the majority of the answers of the students will be wrong. Otherwise, the activity should be considered to be below the student's learning threshold. It is important to know how the teacher behaves in the face of these mistakes.

The explore phase requires students to establish hypotheses by conducting research and share them with their friends. At this stage, almost no students should be expected to give correct answers. Otherwise, the activity is still below the learning threshold. The teacher's guidance task is even more prominent in the research phase than in other stages. At this stage, the teacher has to find the shortcomings and mistakes of the students' predictions and resolve them through his or her activities.

In the elaborate phase, students try to apply the new knowledge they have learned or perform a similar task. At this stage, students should not be expected to apply their newly learned knowledge easily. Therefore, the elaborate process can often lead to the formation and emergence of mistakes. A good understanding of the process of the emergence of mistakes, and how the teacher can guide after the mistakes have come out is needed. However, it is known that there is insufficient information on how to deal with mistakes. In understanding the causes of this deficiency, it will be useful to examine the perspective of teaching approaches toward mistakes.

The perspective of behaviorist theories on the mistake: Mistake is seen as a phenomenon that must be ignored, suppressed (should be punished when it occurs) resulting from the inattention of the student, disruptions in the communication path or wrong reaction (Borasi, 1994; Heinze, 2005; Melis, 2003; Santagata, 2002; Santagata, 2005; Santagata \& Barbieri, 2005; Tsovaltzi et al., 2009).

The perspective of cognitive theories on the mistake: Cognitive theories heeded the misconception and examined its detection, elimination and effects on the learning process. However, as is known, misconceptions are a causal, permanent and persistent cognitive condition that occurs after the completion of a teaching process. The literature on misconceptions carried out by scientists who adopt the cognitive approach is sufficiently comprehensive (detection of misconceptions, elimination of misconceptions, etc.). However, the cognitive literature is not sufficient to explain the mistake and the feedback is given to the mistake. Because the mistakes made by the students are repeated while learning or if the student defends the accuracy of the mistake, it is not a misconception. The students' answers, which are not correct, are incorrect until the subject is finished. For this reason, the perspective of cognitive approaches to the mistake also fails to adequately contribute to teachers about how to deal with mistakes in a student-centered learning environment.

The perspective of constructivist theory on the mistake: Misconceptions are also important in constructivist theory. Because one of the most important obstacles in creating an effective learning environment in student-centered education is seen as misconceptions. For learning, it is necessary to determine the prior knowledge of the students, to remind the basic knowledge on which the learning will be structured and to eliminate misconceptions. A false structuring will cause the subsequent structures to be wrong, thus causing continuous mistakes to be made in the learning environment. Although it is thought that learning without misconception will contribute positively to the later learnings, this is not always true. Students can do mistakes even after an ideal structuring. Therefore, one of the most important problems that constructivist models have to deal with is the mistakes (Santagata, 2002; Santagata, 2005). For this reason, in the constructivist approach, mistakes should be examined as much as misconceptions.

Since the literature on the mistake is mostly focused on detecting and eliminating misconceptions, sufficient strategies for the mistake and combating mistake have not been identified. The teacher's lack of experience and theoretical knowledge about the subject may cause the teacher to be deficient and to fall into a difficult situation in cases where the mistake is to have interfered with the learning process. A sudden mistake creates an effect that increases anxiety and decreases time control for an untrained teacher. This will also cause teachers to be angry and disrupt student-centered environments where students are intended to freely say their thoughts. Teachers are known to resent students who do mistakes in subjects they think are simple, such as definition or term (Heinze, 2005). In fact, there is no reason for the teacher to be angry. Because it should be considered natural to encounter mistakes in the learning environment (Borasi, 1994).

There is limited literature on how teachers should react instantly when they encounter a mistake in the learning process. The majority of these studies were carried out by psychologists and investigated the community's perspectives on the mistake and teachers' perspectives on the mistakes in mathematics (Santagata, 2002; Santagata, 2005; Santagata \& Stigler, 2000; Santagata, 2004; Sterponi \& Santagata, 2000). Perhaps Santagata (2002) conducted the most comprehensive study about mistake and feedbacks to the mistake, which is also a reference source for other studies. Santagata has classified, defined and sampled the mistakes and feedbacks given to the mistakes. The researcher has done and proposed many studies examining the similarities and differences between cultures by emphasizing that the mistake and feedback given to the mistake is a cultural phenomenon (Santagata, 2002; Santagata, 2005; Santagata, 2004; Sterponi \& Santagata, 2000). Nevertheless, when a mistake is encountered, factors other than the cultural components that affect the teacher's behavior have not been adequately revealed. The mistakes', studied by Santagata and other psychologists, place and importance in mathematics and 
the factors affecting the feedback given to the mistake must be studied in detail by the mathematicians. Through these studies, teachers ' perspectives on the mistake and the ways they interfere with the mistake can be determined.

The study aims to identify effective factors that influence teachers' feedback on the mistake. It is known that strong attitudes are effective in shaping behaviors (Krosnick \& Petty, 1995). According to Allport (1935) "attitude in business with 'a mental and neural state of readiness, organized through experience, exerting a directive and dynamic influence upon individual's response to all objects and situations with which it is related" (cited in Malim and Birch (1998)). Attitude is to like or not (Bem, 1970). According to Bloom (1976) the attitude is to have positive thoughts about a lesson or subject, to love or show positive affective characteristics about a lesson, or to have negative thoughts about a lesson and subject, to dislike show negative affective characteristics about a lesson. Attitude is a phenomenon gained through learning that guides to individual behavior and can lead to bias in the decision-making process (Ulgen, 1997). Attitude is the tendency to react positively or negatively that is learned towards certain objects, situations, institutions, concepts or other people (Tezbaşaran, 1997).

Although attitude plays an important role in people's success, it is very difficult to create an attitude towards a certain object or to change the existing attitude. In order to change the attitudes, first, the characteristics of the target audience and the factors that lead to the formation and development of the attitudes must be revealed (Erden, 1995). A qualified attitude scale is needed to determine the factors that lead to the formation and development of attitudes.

The researcher carried out some studies about types of mistakes and techniques used by teachers to give feedback to mistakes (Türkdoğan, Baki, \& Çepni, 2009; Türkdogan \& Baki, 2012; Türkdoğan, 2011). In this process, he realized that affective factors were intensely influential on teachers' perception of mistakes and choosing feedback types. With the help of the scale items prepared within the scope of this study, it was tried to determine mistake and what the dimensions that affect the selection of the methods used to give feedback to the mistake. For this purpose, items containing the dimensions of love, interest, fear, anxiety, pleasure, trust, the existence of the mistake and its role in learning, its importance and the usefulness of giving feedback to the mistakes were written on the scale and it was investigated which of these items were more effective in giving feedback to the mistakes.

\section{Methodology}

\subsection{Participants}

The sample of the study consists of 420 math and science teacher-teacher candidates including 210 men and 210 women. Information about the people in the sample is presented in Table 1.

Table-1. Information about the sample.

\begin{tabular}{|c|c|c|c|c|}
\hline \multirow{2}{*}{ Experience of teachers } & \multicolumn{3}{|c|}{ The branch of the teachers and teacher candidates } & \multirow{2}{*}{ Percentage $(\%)$} \\
\hline & Math & Science & Total & \\
\hline Teacher candidate & 40 & 65 & 105 & $25 \%$ \\
\hline Teacher with $1-5$ years of experience & 50 & 55 & 105 & $25 \%$ \\
\hline Teacher with 6-10 years of experience & 50 & 55 & 105 & $25 \%$ \\
\hline $\begin{array}{l}\text { Teacher with } 11 \text { years and more } \\
\text { experience }\end{array}$ & 60 & 45 & 105 & $25 \%$ \\
\hline Total & 200 & 220 & 420 & $100 \%$ \\
\hline
\end{tabular}

Note: Sampling $(\mathrm{n}=420)$.

As seen in Table 1, the draft scale was applied to 105 teacher candidates ( 40 math, 65 science) who have taught at least 20 lessons within the scope of teaching practice course, 105 teacher (50 math, 55 science) with experience 1-5 years, 105 teacher (50 math, 55 science) with experience 6-10 years, and 105 teacher (60 math, 45 science) with experience 11 years and more.

\subsection{Developing the Attitude Scale of Mathematics and Science Teachers towards Mistake and Instant Feedback to the Mistake}

In the development phase of "Attitude Scale of Mathematics and Science Teachers towards Mistake and Instant Feedback to the Mistake" (MST-AS), which is aimed at determining the attitudes of math and science teachers and teacher candidates towards mistake and instant feedback to the mistake, a pool of item has been created for the trial form. This study was carried out as a continuation of a series of studies previously carried out on the mistake, types of mistakes, instant feedback given to mistake. The knowledge and experiences that the researcher gained from these studies were effective in writing the items in the item pool. Also, studies on attitudes and sub-dimensions and items in these studies were examined (Türkdoğan, 2011). In the creation of items in the item pool, some related items in these scales have been rearranged in the context of mistake and instant feedback to the mistake. So predictive validity is targeted.

Two mathematics educators criticized the items in the item pool in the trial form. These field educators have criticized the items considering the content and construct validity dimensions. Similarly, two linguists examined and rearranged these items. Later, three experts, one of whom was a mathematics educator, one of whom was a science educator and the other a social science educator, criticized the items in the item pool again. After the revisions, language experts reconsidered and edited the items in terms of construct validity. After the arrangements were made, a mathematics and science educator's opinions were received about which sentences were positive and which sentences were negative. Items in which the opinions of the two experts and the researchers regarding the structure of the sentences match remained in the item pool. The items that cannot be matched are rearranged in an environment where these three experts coexist. Also, the writing, punctuation and meaningfulness dimension of the items were reviewed in this meeting. Interviews were made with the five teachers about the trial form and their ideas were taken. In the light of the arrangements, six items were removed from the item pool in the trial form. 
Then, the draft scale was applied as a pilot application to test the construct validity to the 16 elementary mathematics and 19 science teacher candidate who taught in the context of teaching practice course and 7 elementary mathematics and 8 science teachers. As a result of the application, it was determined that there was no item that was not understood in the trial form. There were 48 items in the item pool on the trial form before the actual application.

\subsection{Collecting Data}

The data of the research was collected with the help of the students in the department of mathematics education. While the $2 \mathrm{nd}$, 3rd and 4th-year students who attended the course of the researcher went to their hometown for the semester break, each of them was given some form of MST-AS. The university students, who will apply for the trial form, were given information about how to do the applications. The participating teachers, who will fill out the trial form, were asked to tell the following information before the application started: "All data in this study will be kept confidential and will not be shared with anyone. So do not write your names. Choose the option that best suits how you behave when you encounter a mistake in your classes."

University students applied this trial form to their teachers at the schools they studied in their cities. Not all students were given a trial form and not all students were able to return the forms. Some students brought back 1 form, while others brought back 5 forms.

\subsection{Analysis of the Data}

In this study, exploratory factor analysis (EFA) and confirmatory factor analysis (CFA) were carried out regarding the construct validity of MST-AS. Exploratory factor analysis was made by using SPSS 18.0 and confirmatory factor analysis was made by using Lisrel 8.8 packet program. Item-test score correlations, internal consistency coefficient Cronbach Alfa were calculated. A t-test was carried out to see whether the items discriminated between the upper and lower $27 \%$ of the groups.

Rating on an attitude scales can be made on a five-point ranging from 1 "I totally disagree" to 5 "I totally agree" (Dunn-Rankin, 2004; Tavşancıl, 2005). In this study, scale grading was done as follows: "I totally disagree: 1", "I disagree: 2", "I am indecisive: 3", "I agree: 4" and "I totally agree: 5". The answers of the negative sentences determined in the scale were re-coded in the opposite direction from "I totally agree: 1 " to "I totally disagree: 5 ", "I agree: 2 " to "I disagree: 4 ".

\section{Results}

Before the exploratory factor analysis, the item-test correlations of the trial form included 48 items were calculated and the items, 10, 33 and 38, with the item-test correlation coefficient above .80 were discarded. KaiserMayer-Olkin (KMO) and Bartlett's test for Sphericity was used to test the suitability of the variables in the factor analysis as well as to test the sample size. The KMO value is asked to be greater than .70. This test gives us information about the suitability of the data set and sample size. The analysis concluded that the sample size was "well enough" to perform a factor analysis since the KMO value was=.808>.70 (Brownlow, 2004; Pett, Lackey, \& Sullivan, 2003). Furthermore, when the results of Bartlett's test for Sphericity were examined, it was determined that the chi-square value was significant $\left(\mathrm{X}_{(760)}=1574.81 ; \mathrm{p}<.01\right)$. It has been accepted that data can be factored into these results (Child, 2006; Hutcheson \& Sofroniou, 1999; Pett et al., 2003).

\subsection{Exploratory Factor Analysis}

In order to determine the factor structure of MST-AS, varimax rotation technique was chosen as the factorization method by taking into consideration principal component analysis, clarity and significance (Brownlow, 2004; Walkey \& Welch, 2010).

In exploratory factor analysis, .40 was determined as a cut-off point for the factor load value and the items under this value were ignored $(1,2,3,4,5,6,9,11,12,13,14,18,19,20,21,22,23,28,32,34,35,37,39,41,42$, $43,44,45,46,47)$.

The difference between two high load values in EFA is suggested to be at least .10 (Büyüköztürk, 2009). The criterion that can be taken about entering more than one factor is that there is at least .10 difference between factor loads. Items with a difference of .10 or below between two factor loading are called complex items (Yavuz, 2005).

When the factor load values of the items in the scale were examined, it was determined that item 25 gave a high-value load to more than one factor and that the difference between these factor load values was less than .10. Therefore, this item has been assessed as a complex item and removed from the scale.

Items with low item discrimination, 33 items with factor loadings lower than .40 and 1 complex item with a difference of .10 or below between two factor loading were removed from the scale.

After the items were removed, factor analysis was applied again to the scale, which fell to 14 items (Appendix 1) According to the results of a subsequent EFA, it was decided that the scale could be limited to two factors.

Table-2. Factor loadings of the MST-as and the variances explained.

\begin{tabular}{|c|c|c|c|c|c|}
\hline \multicolumn{3}{|c|}{ External causes } & \multicolumn{3}{|c|}{ Internal causes } \\
\hline Item No & Factor Loading & Explained Variance & Item No & Factor Loading & Explained Variance \\
\hline 7 & .722 & \multirow{7}{*}{$25.45 \%$} & 16 & .653 & \multirow{7}{*}{$24.55 \%$} \\
\hline 8 & .624 & & 17 & .644 & \\
\hline 15 & .711 & & 24 & .703 & \\
\hline 26 & .789 & & 27 & .684 & \\
\hline 30 & .698 & & 29 & .769 & \\
\hline 31 & .736 & & 40 & .728 & \\
\hline 36 & .605 & & 48 & .632 & \\
\hline
\end{tabular}

Explained Variance: $50.00 \%$ 
The first factor contributed $25.45 \%$ and the second factor contributed $24.55 \%$ to the total variance. The twofactor structure of the scale was found to explain $50 \%$ of the total variance and have 14 items. This ratio is sufficient for multifactorial patterns (Brownlow, 2004; Fabrigar \& Wegener, 2011; Hutcheson \& Sofroniou, 1999). Details of the scale's factor loadings and the variances explained are provided in Table 2.

As shown in Table 2, the factor loadings of 7 items under the external causes range from .605 to .789, the factor loadings of 7 items under the internal causes range from .632 to .769 .

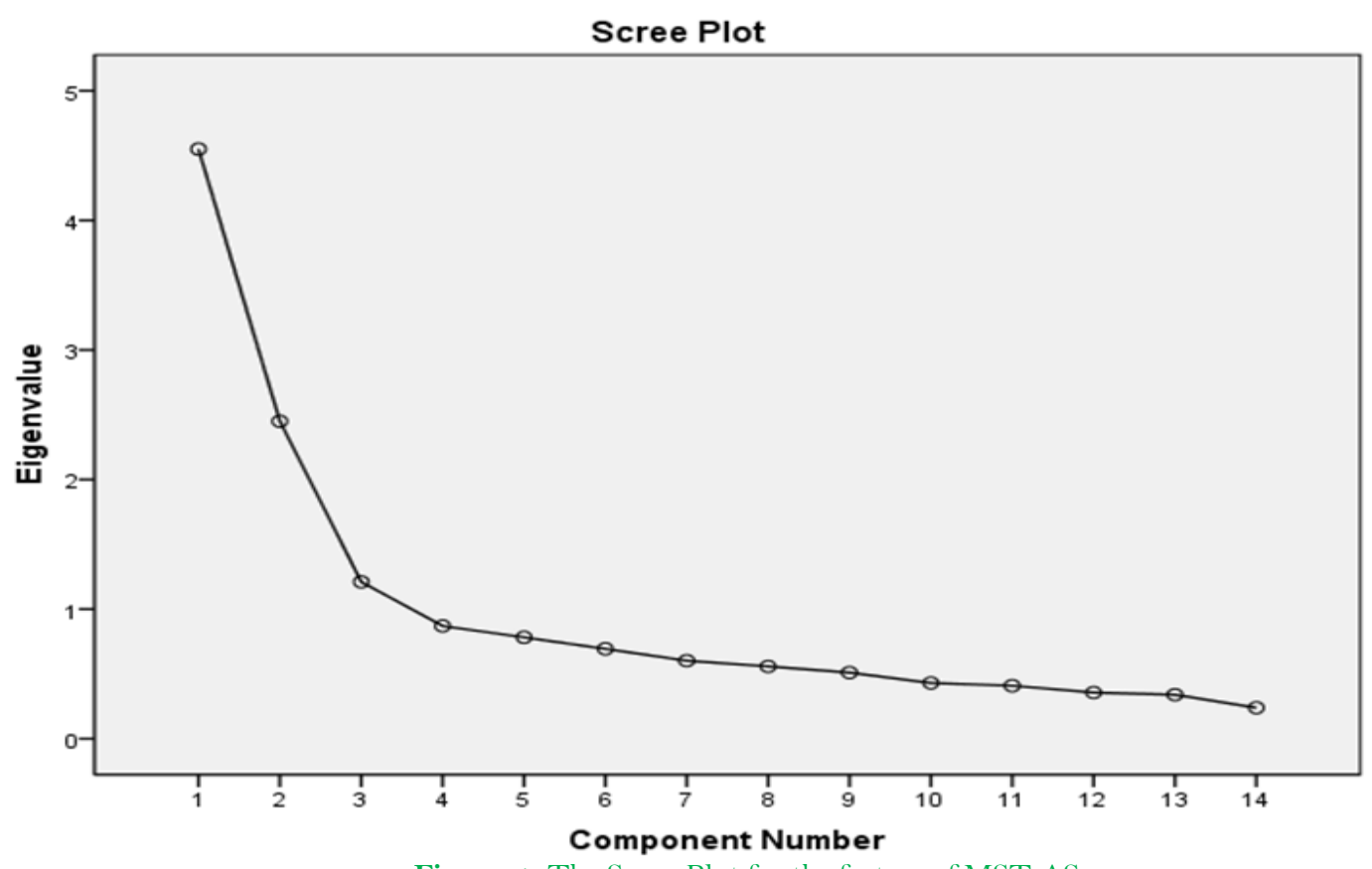

Figure-1. The Scree-Plot for the factors of MST-AS.

When the Scree-Plot Graphic with the eigenvalues on the vertical axis and the factors on the horizontal axis is examined (Figure-1), it is seen that the high acceleration decline decreases after the fourth point. Points indicate the degree of contribution to the variance of the descent tendency seen from the first point, and each interval between two points means a factor (Çokluk, Şekercioğlu, \& Büyüköztürk, 2012). It was decided to perform the analysis for two factors according to the eigenvalue, variance percentages and the data obtained from the ScreePlot Graphic.

\subsection{Item-Total Correlations}

The item-test correlation values describing the validity coefficient of each item are provided in Table 3.

Table-3. The item-test correlation of the MST-AS

\begin{tabular}{|c|c|c|c|c|c|c|c|c|c|c|c|c|c|c|}
\hline \multirow[t]{2}{*}{ Factors } & \multicolumn{14}{|c|}{ Items } \\
\hline & 7 & 8 & 15 & 26 & 30 & 31 & 36 & 16 & 17 & 24 & 27 & 29 & 40 & 48 \\
\hline External causes & .673 & .621 & .732 & .770 & .735 & .725 & .683 & & & & & & & \\
\hline Internal causes & & & & & & & & .690 & .659 & .727 & .666 & .751 & .752 & .628 \\
\hline Total & .435 & .464 & .570 & .507 & .546 & .498 & .545 & .575 & .595 & .700 & .549 & .671 & .661 & .534 \\
\hline
\end{tabular}

As shown in Table 3, the correlation coefficients of items within the external causes factors in the scale vary between .621 and .770 . These values show that items 7,8 and 36 items have a medium level (.30-.70) and items 15, 26, 30 and 31 items have a high level (.70-1.00) item-test correlation. The correlation coefficients of the items within the internal causes factor in the scale vary between .628 and .752 . These values show that items 16, 17, 27 and 48 have a medium level (.30-.70) and items 24, 29 and 40 have a high level (.70-1.00) item-test correlation.

The total correlation coefficients of the items in the scale vary between .435 and .700 . These values show that items other than item 24 have a medium level (.30-.70) and item 24 has a high level (.70-1.00) item-test correlations (Brownlow, 2004; Hutcheson \& Sofroniou, 1999).

Table-4. Correlations between Factor Scores of the MST-AS.

\begin{tabular}{l|c|c|c}
\hline \multirow{2}{*}{ Factors } & \multicolumn{3}{|c}{ Correlations } \\
\cline { 2 - 4 } & $\mathbf{1 . ~ b o y u t}$ & $\mathbf{2 . ~ b o y u t}$ & Total \\
\hline External causes & 1 & $.310^{* *}$ & $.727^{* *}$ \\
\hline Internal causes & $.310^{* *}$ & 1 & $.878^{* *}$ \\
\hline Total & $.727^{* *}$ & $.878^{* *}$ & 1 \\
\hline Note: ${ }^{*} \mathrm{p}<.01$.
\end{tabular}

As seen in Table 4, there is a weak correlation between the External causes dimension and the Internal causes dimension (.310), and a high level (.727) -very high level (.878) correlation between the sub-dimensions and the scale total.

\subsection{Item Discrimination}

An independent sample T-test was used to determine the distinguishing strength of the substances on the scale. Item discrimination for each item was obtained via computing the difference between mean item scores of participants allocated in the upper $27 \%$ and lower $27 \%$ of the sample according to their composite scale scores. The calculated independent sample t-test values were shown in Table 5. 


\begin{tabular}{|c|c|c|c|c|c|c|}
\hline Item & Group 27\% & $\mathbf{N}$ & $\mathrm{X}$ & Ss & $\mathrm{t}$ & $p$ \\
\hline \multirow{2}{*}{7} & Upper & 113 & 4.9115 & .41312 & \multirow{2}{*}{5.591} & \multirow{2}{*}{.000} \\
\hline & Lower & 113 & 4.4690 & .73279 & & \\
\hline \multirow[t]{2}{*}{8} & Upper & 113 & 5.0000 & .00000 & \multirow{2}{*}{6.652} & \multirow{2}{*}{.000} \\
\hline & Lower & 113 & 4.4336 & .90511 & & \\
\hline \multirow{2}{*}{15} & Upper & 113 & 4.9292 & .25763 & \multirow{2}{*}{10.682} & \multirow{2}{*}{.000} \\
\hline & Lower & 113 & 3.8850 & 1.00669 & & \\
\hline \multirow[t]{2}{*}{26} & Upper & 113 & 4.8584 & .35019 & \multirow{2}{*}{7.393} & \multirow{2}{*}{.000} \\
\hline & Lower & 113 & 4.2124 & .86035 & & \\
\hline \multirow{2}{*}{30} & Upper & 113 & 4.9646 & .18561 & \multirow{2}{*}{11.894} & \multirow{2}{*}{.000} \\
\hline & Lower & 113 & 3.8938 & .93887 & & \\
\hline \multirow{2}{*}{31} & Upper & 113 & 5.0000 & .00000 & \multirow{2}{*}{10.183} & \multirow{2}{*}{.000} \\
\hline & Lower & 113 & 4.2478 & .78525 & & \\
\hline \multirow{2}{*}{36} & Upper & 113 & 4.8584 & .39792 & \multirow{2}{*}{9.964} & \multirow{2}{*}{.000} \\
\hline & Lower & 113 & 3.8584 & .98983 & & \\
\hline \multirow{2}{*}{16} & Upper & 113 & 4.3894 & .77268 & \multirow{2}{*}{14.326} & \multirow{2}{*}{.000} \\
\hline & Lower & 113 & 2.5398 & 1.13417 & & \\
\hline \multirow{2}{*}{17} & Upper & 113 & 4.8584 & .44052 & \multirow{2}{*}{10.398} & \multirow{2}{*}{.000} \\
\hline & Lower & 113 & 3.6726 & 1.12949 & & \\
\hline \multirow{2}{*}{24} & Upper & 113 & 4.9115 & .28528 & \multirow{2}{*}{18.166} & \multirow{2}{*}{.000} \\
\hline & Lower & 113 & 3.1858 & .96869 & & \\
\hline \multirow{2}{*}{27} & Upper & 113 & 4.4071 & .56120 & 12979 & 000 \\
\hline & Lower & 113 & 3.2035 & .87790 & 12.279 & .000 \\
\hline 90 & Upper & 113 & 4.9823 & .13244 & 15974 & $0 \cap 0$ \\
\hline 29 & Lower & 113 & 3.5221 & 1.00087 & 15.374 & .000 \\
\hline 40 & Upper & 113 & 4.4690 & .82452 & 15.979 & 000 \\
\hline 40 & Lower & 113 & 2.7257 & .87880 & 15.379 & .000 \\
\hline & Upper & 113 & 4.9204 & .27195 & 11099 & 000 \\
\hline 48 & Lower & 113 & 3.7345 & 1.11016 & 11.029 & .000 \\
\hline
\end{tabular}

As seen in Table 5, there is a significant difference between the upper and lower groups $(\mathrm{p}<.01)$. This significant differentiation is an indication that the items on the scale have the desired level of discrimination (Brownlow, 2004).

\subsection{Confirmatory Factor Analysis (CFA)}

The validity of the two-factor structure derived from the EFA was tested with CFA. The results obtained from the CFA are in Table 6 and Figure 2.

\begin{tabular}{|c|c|c|c|}
\hline Fit Indices & Values & Acceptable Fit & Good Fit \\
\hline Chi-Square $\left(\mathrm{X}^{2}\right)$ & 1574.8 & & \\
\hline Degrees of Fredom (SD) & 760 & & \\
\hline Chi-Square/sd & $2.07 *$ & $2 \leq \mathrm{X}^{2} / \mathrm{sd} \leq 3$ & $.00 \leq \mathrm{X}^{2} / \mathrm{sd}<2$ \\
\hline RMSEA & $.022 * *$ & $.05 \leq$ RMSEA $\leq .10$ & $.00 \leq$ RMSEA $<.05$ \\
\hline NFI & $.91 * * *$ & $.90 \leq \mathrm{NFI} \leq .95$ & $.95 \leq \mathrm{NFI} \leq 1.00$ \\
\hline NNFI & $.88 * * *$ & $.95 \leq \mathrm{NNFI} \leq .97$ & $.97 \leq \mathrm{NNFI} \leq 1.00$ \\
\hline SRMR & $.014^{* * *}$ & $.05 \leq \mathrm{SRMR} \leq .10$ & $.00 \leq \mathrm{SRMR}<.05$ \\
\hline GFI & $.75 * * *$ & $.90 \leq \mathrm{GFI} \leq .95$ & $.95 \leq \mathrm{NFI} \leq 1.00$ \\
\hline AGFI & .69 **** & $.85 \leq \mathrm{AGFI} \leq .90$ & $.90 \leq \mathrm{ANFI} \leq 1.00$ \\
\hline RMR & $.098 * * * *$ & $.05 \leq \mathrm{RMR} \leq .10$ & $.00 \leq \mathrm{RMR} \leq .05$ \\
\hline RFI & $.78 * * *$ & $.90 \leq \mathrm{RFI} \leq .95$ & $.95 \leq \mathrm{RFI} \leq 1.00$ \\
\hline IFI & $.83 * * *$ & $.90 \leq \mathrm{IFI} \leq .95$ & $.95 \leq \mathrm{IFI} \leq 1.00$ \\
\hline p- Value & .000 & & \\
\hline
\end{tabular}

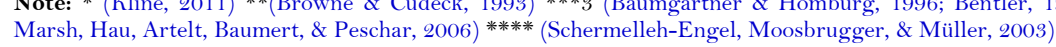

The fit indices of the 14-item model were analyzed using CFA. The results of the CFA concluded the following (see, Table 6 and Figure 2): $\mathrm{X}^{2} / \mathrm{df}=2.07$, SRMR $=.014$, RMSEA $=.022, \mathrm{RMR}=.098, \mathrm{AGFI}=.69$, GFI $=.75, \mathrm{NFI}$ $=.91, \mathrm{NNFI}=.88, \mathrm{RFI}=.78$, and IFI $=.83$. Given that the GFI, AGFI, NNFI, RFI and IFI values fell below .90, one can state that it had a weak fit. However, the RMR value being less than .10 shows us that model-data compatibility was acceptable. The $\mathrm{X}^{2} / \mathrm{df}$ and NFI values also demonstrate acceptable compatibility. The RMSEA and SRMR values also demonstrate good compatibility as well. The fit indices for the scale were deemed acceptable within in the context of the CFA results (Bartholomew, Knott, \& Moustaki, 2011; Brown, 2006; Schermelleh-Engel et al., 2003; Schumacker \& Lomax, 2004; Thompson, 2004). 


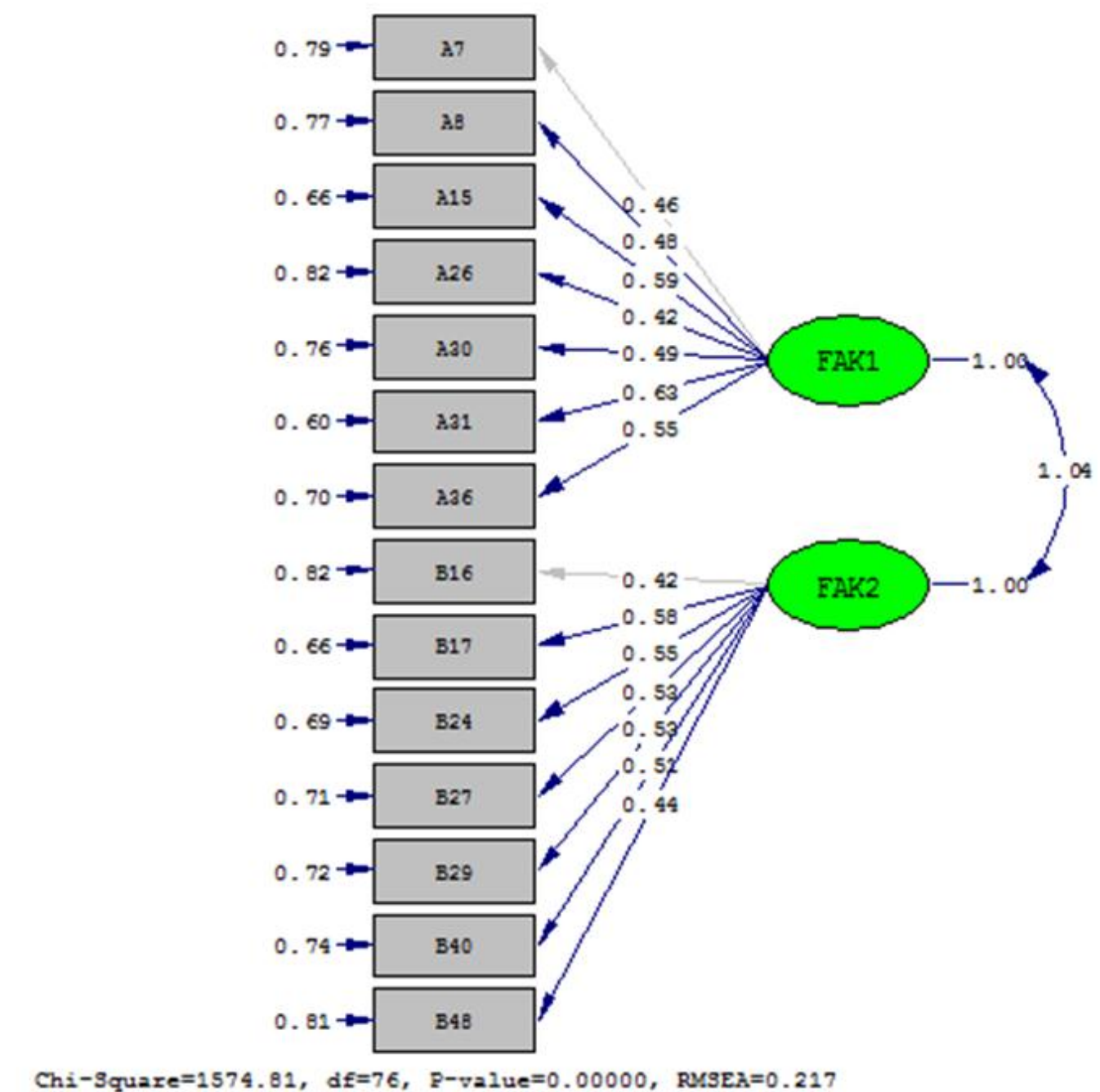

Figure-2. Path diagram for CFA results of the MST-AS. FAK1: External causes: FAK2: Internal causes.

When the diagram is examined, the factor load value of each item is above $.40 \mathrm{in}$, so each of the items is compatible with the factors.

\subsection{Findings Regarding the Reliability of the Scale}

The reliability analysis of the MST-AS was calculated using Cronbach's alpha reliability coefficient. Cronbach Alpha reliability coefficients of scale are given in Table 7 .

\begin{tabular}{l|c}
\multicolumn{2}{c}{ Table-7. Cronbach Alpha reliability coefficients of MST-AS. } \\
\hline Factors & Cronbach Alpha reliability coefficients \\
\hline External causes & .828 \\
\hline Internal causes & .817 \\
\hline Scale & .829 \\
\hline Source: Obtained from primary data.
\end{tabular}

Cronbach Alpha reliability coefficient was calculated as .829 for the scale. The Cronbach Alpha reliability coefficient was calculated as .828 for the external causes dimension and as .828 for the external causes dimension as .817. These results are proof that sub-scales of the MST-AS are reliable (Brownlow, 2004).

\section{Conclusions and Recommendations}

The research aims is to develop a valid and reliable attitude scale that can measure the attitudes of math and science teachers and teacher candidates towards mistakes and instant feedback to mistake. For this purpose, a pool of items was established in the relevant field literature, expert opinions were taken about the items and finally, a pilot application phase was carried out by preparing a trial form.

Before the exploratory factor analysis, the item-test correlations of the trial form included 48 items were calculated and three items with the item-test correlation coefficient above .80 were discarded.

Kaiser-Mayer-Olkin (KMO) and Bartlett's test for Sphericity was used to test the suitability of the variables in the factor analysis as well as to test the sample size KMO value was calculated as .808. Besides, as a result of the Bartlett's test for Sphericity, the chi-square value was determined to be significant $\left(\mathrm{X}_{(760)}^{2}=1574.81 ; \mathrm{p}<.01\right)$.

In exploratory factor analysis, .40 was determined as a cut-off point for the factor load value and 33 items under this value were ignored.

Since one item gave a high-value load to more than one factor and that the difference between these factor load values was less than .10, this item has been assessed as a complex item and removed from the scale.

After the items were removed, the exploratory factor analysis was re-applied form. According to the results of the subsequent EFA, it was decided that the scale has two factors, external causes and internal causes, with an eigenvalue greater than 1.

According to the results of performed confirmatory factor analysis (CFA) to determine the structural validity of MST-AS, $\mathrm{X}^{2} / \mathrm{df}$ ratio $(1574.8 / 760=2.07)$ is acceptable to see Table 6. 
The model has a good fit due to its RMSEA value .022 and SRMR value of .014, and acceptable fit due to its NFI value of .91. These results show that the scale is compatible with real data see Table 6.

When Table 6 is analyzed, since it is understood that all the compliance values are within the acceptable limits, it is seen that the two-factor structure of the MST-AS is a usable and valid model.

Cronbach Alpha reliability coefficient was calculated as .829 for the scale, as .828 for the external causes dimension and as .828 for the external causes dimension as .817 . These results are proof that sub-scales of the MST-AS are reliable.

The MST-AS is a valid and reliable scale that can be used in experimental and descriptive research to determine the attitudes of math and science teachers and teacher candidates towards mistakes and instant feedback to mistake.

\section{References}

Allport, G. W. (1935). Attitudes. In C. M. Murchison (Ed.), Handbook of social psychology. Worcester, MA: Clark University Press.

Bartholomew, D. J., Knott, M., \& Moustaki, I. (2011). Latent variable models and factor analysis: A unified approach. West Sussex Wiley.

Baumgartner, H., \& Homburg, C. (1996). Applications of structural equation modeling in marketing and consumer research: A review. International Journal of Research in Marketing, 13(2), 139-161.

Bem, D. J. (1970). Beliefs, attitudes and human affairs. California: Belmont Publishing.

Bentler, P. M. (1980). Multivariate analysis with latent variables: Causal modeling. Annual Review of Psychology, 31(1), 419-456.

Bentler, P., \& Bonett, D. G. (1980). Significance tests and goodness of fit in the analysis of covariance structures. Psychological Bulletin, 88(3), $5 \mathrm{SS}-606$.

Bloom, B. S. (1976). Human characteristics and school learning. New York: McGraw-Hill.

Borasi, R. (1994). Capitalizing on errors as" springboards for inquiry": A teaching experiment. Journal for Research in Mathematics Education, 25(2), 166-208.

Brown, T. A. (2006). Confirmatory factor analysis for applied research. New York: Guilford Press.

Browne, M. W., \& Cudeck, R. (1993). Alternative ways of assessing model fit. In: Bollen, K.A., \& Long, J.S. (Eds.). Testing structural equation models (pp. 136-162). Beverly Hills, CA: Sage.

Brownlow, C. (2004). SPSS explained. London: Routledge.

Büyüköztürk, Ş. (2009). Manual of data analysis for social sciences. Ankara: Pegem Academy.

Child, D. (2006). The essentials of factor analysis. London: Continuum International Publishing Group.

Çokluk, Ö., Şekercioğlu, G., \& Büyüköztürk, Ş. (2012). Multivariate statistics for social sciences SPSS and LISREL applications (2nd ed.). Ankara: Pegem Akademi Publishing.

Dunn-Rankin, P. (2004). Scaling methods. London: Routledge.

Erden, M. (1995). Attitudes of teacher candidates towards teaching certificate courses. Hacettepe University Journal of Education Faculty, 11, 99-104.

Fabrigar, L. R., \& Wegener, D. T. (2011). Exploratory factor analysis. Oxford: Oxford University Press.

Heinze, A. (2005). Mistake-handling activities in German mathematics classroom. In H. L. Chick \& J. L. Vincent (Eds.). Paper presented at the Proceedings of the 29th Conference of the International Group for the Psychology of Mathematics Education. Melbourne (Australien): PME.

Hutcheson, G. D., \& Sofroniou, N. (1999). The multivariate social scientist: Introductory statistics using generalized linear models. Thousand Oaks, CA: Sage.

Kline, R. B. (2011). Principles and practice of structural equation modeling. New York: The Guilford Press.

Krosnick, J. A., \& Petty, R. E. (1995). Attitude strength: An overview. In R. E. Petty \& J. A. Krosnick (Eds.), Ohio State University series on attitudes and persuasion. Attitude strength: Antecedents and consequences (Vol. 4, pp. 1-24): Lawrence Erlbaum Associates, Inc.

Malim, T., \& Birch, A. (1998). Introductory psychology. London: Palgrave.

Marsh, H. W., Hau, K.-T., Artelt, C., Baumert, J., \& Peschar, J. L. (2006). OECD's brief self-report measure of educational psychology's most useful affective constructs: Cross-cultural, psychometric comparisons across 25 countries. International Journal of Testing, 6(4), 31 1360.

Melis, E. (2003). Design of erroneous examples for ActiveMath. In Ch.-K. Looi, G. McCalla, B.B., Breuker, J. (Eds.), Artificial Intelligence in Education. Supporting Learning Through Intelligent and Socially Informed Technology. Paper presented at the 12th International Conference, (AIED 2005).

Pett, M. A., Lackey, N. R., \& Sullivan, J. J. (2003). Making sense of factor analysis: The use of factor analysis for instrument development in health care research. Thousand Oaks, CA: Sage.

Santagata, R. (2002). When student make mistake: Socialization practices in Italy and the United States. Doctoral Dissertation, Los Angelels: University of California, Philosophy in Psychology.

Santagata, R. (2005). Practices and beliefs in mistake-handling activities: A video study of Italian and US mathematics lessons. Teaching and Teacher Education, 21(5), 491-508.

Santagata, R., \& Barbieri, A. (2005). Mathematics teaching in Italy: A cross-cultural video analysis. Mathematical thinking and learning, 7(4), 291-312.

Santagata, R., \& Stigler, J. W. (2000). Teaching mathematics: Italian lessons from a cross-cultural perspective. Mathematical Thinking and Learning, 2(3), 191-208.

Santagata, R. (2004). “Are you joking or are you sleeping?" Cultural beliefs and practices in Italian and US teachers' mistake-handling strategies. Linguistics and Education, 15(1-2), 141-164.

Schermelleh-Engel, K., Moosbrugger, H., \& Müller, H. (2003). Evaluating the fit of structural equation models: Tests of significance and descriptive goodness-of-fit measures. Methods of Psychological Research Online, 8(2), 23-74.

Schumacker, R. E., \& Lomax, R. G. (2004). A beginner's guide to structural equation modeling. London: Lawrence Erlbaum Associates.

Sterponi, L., \& Santagata, R. (2000). Mistakes in the classroom and at the dinner table: A comparison between socialization practices in Italy and the United States. Crossroads of Language, Interaction, and Culture, 3, 57-72.

Tavşancıl, E. (2005). Measuring attitudes and data analysis with SPSS. Ankara: Nobel Publications.

Tezbaşaran, A. A. (1997). Likert type scale development guide. Ankara: Turkish Psychologists Association.

Thompson, B. (2004). Exploratory and confirmatory factor analysis. Washington, DC: American Psychological Association Press.

Tsovaltzi, D., Melis, E., Mclaren, B., M., Dietrich, M., Goguadze, G., \& Meyer, A. (2009). Erroneous examples: A preliminary investigation in to learning benefits. Paper presented at the Fourth European Conference on Technology Enhanced Learning, Learning in the Synergy of Multiple Disciplines, Berlin, Heidelberg.

Türkdoğan, A., Baki, A., \& Çepni, S. (2009). The anatomy of mistakes: Categorizing students' mistakes in mathematics within learning theories. Turkish Journal of Computer and Mathematics Education, 1(1), 13-26.

Türkdogan, A., \& Baki, A. (2012). Primary school second grade mathematic teachers' feedback strategies to students' mistakes. Ankara University, Journal of Faculty of Educational Sciences, 45(2), 157-182.

Türkdoğan, A. (2011). Anatomy of wrong: Mistakes made by students in elementary mathematics classes and analytical analysis of teachers' Feedback. PhD Thesis, Karadeniz Technical University, Institute of Educational Sciences, Trabzon.

Ulgen, G. (1997). Educational psychology. Istanbul: Alkim Publishing.

Walkey, F., \& Welch, G. (2010). Demystifying factor analysis: How it works and how to use it. Bloomington: Xlibris, Corp.

Yavuz, S. (2005). Developing a technology attitude scale for pre-service chemistry teachers. Turkish Online Journal of Educational Technology, $4(1), 17-25$. 
Appendix-1. The MST-AS.

Development of an Attitude Scale of Mathematics and Science Teachers towards Mistake and Instant Feedback to the Mistake: A Validity and Reliability Study (MST-AS).

\begin{tabular}{|c|c|c|c|c|c|c|}
\hline \multicolumn{2}{|c|}{ 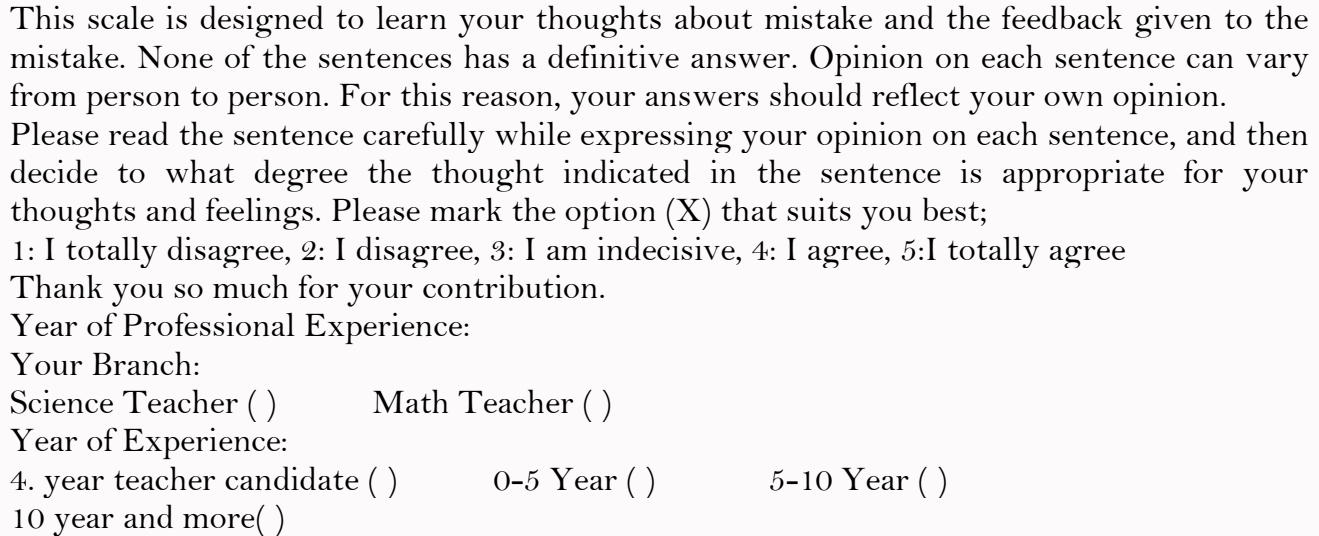 } & 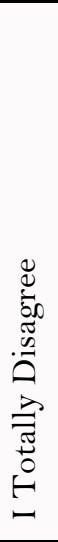 & 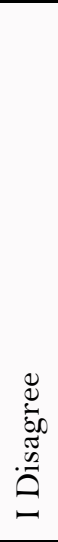 & $\begin{array}{l}0 \\
\frac{0}{\pi} \\
\frac{2}{0} \\
\frac{0}{0} \\
\Xi \\
\Xi \\
\Xi \\
-\end{array}$ & 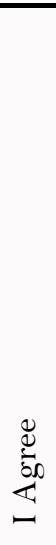 & 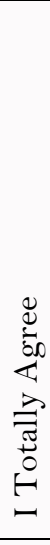 \\
\hline ฮี & * 7 . Trying to understand the reason for students' mistakes is a waste of time. & & & & & \\
\hline \multirow{6}{*}{ 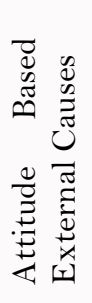 } & $\begin{array}{l}\text { *8. There is nothing beneficial for the student to try to give feedback to the } \\
\text { mistakes. }\end{array}$ & & & & & \\
\hline & *15. If I do not feel compulsory, I will not give any feedback to the mistakes. & & & & & \\
\hline & *26. I feel insecure when I have to deal with mistake. & & & & & \\
\hline & *30. Even hearing the name of the mistake makes me uneasy. & & & & & \\
\hline & *31. If I could, I would ignore the wrongs. & & & & & \\
\hline & *36. I feel so helpless when dealing with mistakes. & & & & & \\
\hline \multirow{7}{*}{ 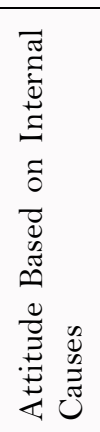 } & $\begin{array}{l}\text { 17. Knowing and understanding the mistake better makes me a better } \\
\text { teacher. }\end{array}$ & & & & & \\
\hline & $\begin{array}{l}\text { 24. It gives me pleasure to give feedback to the student who did mistake in } \\
\text { class. }\end{array}$ & & & & & \\
\hline & 27. I am assertive to give feedback to the mistake. & & & & & \\
\hline & 29. I enjoy trying to understand the reason of the mistakes. & & & & & \\
\hline & 40. I enjoy dealing with students' mistakes. & & & & & \\
\hline & $\begin{array}{l}\text { 48. It gives me pleasure to get the student who did a mistake in the lesson to } \\
\text { the truth through feedback. }\end{array}$ & & & & & \\
\hline & 16. As I understand the causes of the mistakes, I love the mistakes even more. & & & & & \\
\hline
\end{tabular}

Note: * 7. 8. 26. 30. 31 ve 44. items are attitude phrases with negative meaning.

** Items that have negative meaning should be analyzed by inverting. 